\title{
Health-related quality of life among cognitively intact nursing home residents with and without cancer - a 6-year longitudinal study
}

This article was published in the following Dove Press journal:

Patient Related Outcome Measures

27 April 2017

Number of times this article has been viewed

\section{Jorunn Drageset ${ }^{1,2}$ \\ Geir Egil Eide ${ }^{3,4}$ \\ Anne Corbett ${ }^{5}$}

'Department of Nursing, Faculty of Health and Social Sciences, Western Norway University of Applied Sciences, ${ }^{2}$ Department of Public Health and Primary Health Care, University of Bergen, ${ }^{3}$ Centre for Clinical Research, Western Norway Health Region Authority, ${ }^{4}$ Department of Public Health and Primary Health Care, University of Bergen, Bergen, Norway; Institute of Health Research, Exeter University Medical School, University of Exeter, Exeter, UK
Correspondence: Jorunn Drageset Faculty of Health and Social Sciences, Western Norway University of Applied Sciences, Inndalsveien 28, N-5063 Bergen, Norway

Tel +4755 585589

$\mathrm{Fax}+4755585556$

Email Jorunn.Drageset@hvl.no
Background: Limited information exists regarding the natural development of health-related quality of life (HRQOL) and its determinants among mentally intact nursing home (NH) residents. We aimed to examine HRQOL over time during a 6-year period among residents of NHs, who are not cognitively impaired, and to examine whether sense of coherence and a diagnosis of cancer influence HRQOL.

Methods: The study was prospective and included baseline assessment and 6-year follow-up. After baseline assessment of 227 cognitively intact NH residents (Clinical Dementia Rating score $\leq 0.5$ ), we interviewed 52 living respondents a second time at the 5-year follow-up and 18 respondents a third time at the 6-year follow-up. We recorded data from the interviews using the Short Form-36 (SF-36) Health Survey and the Sense of Coherence Scale. To study different developments over time for residents without and with cancer, we tested interactions between cancer and time.

Results: The subscores of physical functioning and role limitation-physical domains declined with time ( $P<0.001$ and $P=0.02$, respectively). Having a diagnosis of cancer at baseline was negatively correlated with general health $(P=0.002)$. Sense of coherence at baseline was positively correlated with all the SF-36 subscores from baseline to follow-up $(P<0.001)$.

Conclusion: The study indicates that the HRQOL changed over time during the 6 years of follow-up, and the sense of coherence appeared to be an important component of the HRQOL. Finally, our results showed that having a diagnosis of cancer was associated with decline in the general health subdimension.

Keywords: health-related quality of life, nursing home, cancer, follow-up, sense of coherence

\section{Introduction}

Life expectancy is increasing worldwide. ${ }^{1}$ The expanding number of older adults is resulting in increased pressure on health care services and long-term care provision, resulting in considerable fiscal burden to governments around the world. In Norway, $70 \%$ of people older than 80 years reside in full-time care institutions. ${ }^{2}$ This is comparable with figures reported in the $\mathrm{US}^{3}$ and across the European Union. ${ }^{4}$ The move to a nursing home (NH) is usually triggered by increasing frailty, loss of independence, and poor health, and residents often need assistance in completing daily tasks and personal care. ${ }^{5}$ This change of situation and loss of autonomy resulting from aging can strongly influence well-being and mental health, and this is often overlooked among residents who are otherwise cognitively healthy. Health-related quality of life (HRQOL) is, therefore, a major issue among NH residents. A key additional factor 
in the HRQOL among NH residents is chronic illness and comorbidity. ${ }^{6,7}$ Cancer is common, affecting up to $26 \%$ of people on admission. ${ }^{8,9}$ It is associated with several key symptoms, including pain, nausea, dyspnea, and fatigue, all of which influence HRQOL. ${ }^{9-13}$

Several studies have examined HRQOL across populations, ${ }^{14-18}$ with a general consensus across the studies that HRQOL gradually declines with age, as measured by the validated Short Form-36 (SF-36) Health Survey, with the steepest decline among people older than 80 years. ${ }^{16}$ This evidence includes one large longitudinal study of 6539 women and 2884 men from a general population of nine cities and surrounding rural areas in Canada over a 5-year period (1996/1997-2001/2002) that reported a clear age-related decline in HRQOL, especially related to physical decline. Age-related decline in HRQOL is also reported among $\mathrm{NH}$ residents. ${ }^{19-21}$ Our previously published work has described the impact of cancer on HRQOL among NH residents, reporting lower HRQOL and a higher rate of hospital admissions among cognitively intact $\mathrm{NH}$ residents with a diagnosis of cancer compared with people without cancer. ${ }^{7,8}$

One previously unexplored potential factor in HRQOL in care homes is coping, as a sense of coherence. The construct of sense of coherence is based on Antonovsky's ${ }^{22}$ theory of salutogenesis, in which stress in the sense of tension and appropriate load is viewed as potentially promoting health. The assumption is that a strong sense of coherence is associated with the resources to cope with stressful life events or situations. Sense of coherence contains three components: comprehensibility, manageability, and meaningfulness. Further, sense of coherence indicates individuals' general resistance resources and their ability to use them. General resistance resources represent integral, biological, material, and psychosocial resources supporting individuals in perceiving their lives as consistent, structured, and understandable. Coping has been shown to be an important resource in relation to HRQOL among older people living in the community, in hospital settings, ${ }^{23-25}$ and NHs ${ }^{26}$ Further, sense of coherence has been shown to be important in relation to health ${ }^{27-29}$ and hospitalization for older people. ${ }^{30}$ The relationship between sense of coherence and cancer among $\mathrm{NH}$ residents has not yet been explored. NHs emphasize mental and physical well-being for the residents as an internationally recognized goal, ${ }^{31}$ and this is considered an important indicator of health outcome. ${ }^{32}$ For the treatment of individual people in cancer care, prolonging survival and maintaining or improving HRQOL are highlighted as two important goals. ${ }^{33}$ In this context, studying HRQOL over time in relation to sense of coherence may provide important information regarding the most appropriate treatment and care approaches for people with cancer. This study, therefore, sought to examine HRQOL among cognitively intact adults living in $\mathrm{NH}$ and to establish whether sense of coherence and having a diagnosis of cancer influence HRQOL for these individuals.

\section{Methods \\ Design and setting}

This was a prospective study carried out in 30 NHs in Norway that was conducted as part of an ongoing HRQOL study among 227 cognitively intact NH residents: 60 with a diagnosis of cancer and 167 without. We invited all NHs in this cohort that offered long-term residential care to participate. We contacted the managers of the NHs included at baseline 5 and 6 years later for follow-up data collection. The principal investigator (JD) who also performed all interviews directly contacted all managers at the NHs and the respondents. No resident was contacted without previous written informed consent from the resident and the management. The Norwegian Social Science Data Services and the Western Norway Regional Committee for Medical and Health Research Ethics approved the study (REK. Vest nr. 162.03/2009/1550).

\section{Participants}

We recruited residents with no cognitive impairment in 2009 and followed up after 5 and 6 years. All residents were living in the same $\mathrm{NH}$ at follow-up as at baseline. The inclusion criteria at baseline (and both follow-ups) were as follows: age 65 years and older, cognitively intact, capable of carrying out a conversation, as assessed by a physician, and residing in the NH for at least 6 months. Cognitively intact was defined as having a Clinical Dementia Rating (CDR) of $\leq 0.5^{34}$ as assessed by trained nurses who had observed participants for 4 weeks before baseline. The CDR is a widely used clinical measure for dementia comprising a global score derived from six domains of cognitive and functional performance: memory, orientation, judgment and problem-solving, community affairs, home and hobbies and personal care. ${ }^{35}$ We also applied the CDR before follow-up. The same principal investigator (JD) who had performed the baseline interviews ( $n=227$ ) carried out the follow-up interviews. We obtained written informed consent from all participants.

\section{Outcome measures}

\section{Demographic and medical information}

We assessed sociodemographic and clinical data such as age, sex, and comorbidity from the residents' medical 
records. We assessed comorbidity (not cancer) using the Functional Comorbidity Index (FCI), a clinically based index ${ }^{36}$ that includes the sum of 18 diagnoses (not cancer), scored 1 for "yes" and 0 for "no" as recommended by Groll et al. ${ }^{36}$ The maximum score (18) indicates the maximum number of comorbid illnesses among NH residents. ${ }^{36}$ The FCI does not include cancer diagnoses, so we obtained these separately. The residents with cancer had cancer at baseline. All cancer diagnoses were included, including skin cancer (basal cell carcinoma). We obtained the cancer diagnoses from medical records and included active cancer and previously treated cancer. Cancer diagnoses may have changed over time, but in this study, we wanted to analyze the relationship between cancer and HRQOL 5 and 6 years after the initial interview.

\section{HRQOL}

We measured HRQOL at baseline and after 5 and 6 years using the SF-36 Health Survey, ${ }^{37}$ which has been used extensively in observational studies and clinical trials among individuals with a wide range of illnesses, ages, and other characteristics. ${ }^{38,39}$ It has demonstrated high reliability (Cronbach's alpha: $0.72-0.94),{ }^{40,41}$ good construct validity, ${ }^{40}$ and convergent validity. ${ }^{42}$ The SF-36 comprises 36 questions (items) along eight dimensions: physical functioning (10 items), general health (five items), mental health (five items), bodily pain (two items), role limitation related to physical problems (four items), role limitation related to emotional problems (three items), social functioning (two items), and vitality (four items). An additional item, reported health transition, notes changes in general health over the past year. The response scores for each dimension are added, and the total is converted to a score between 0 and 100 (highest). ${ }^{37,43}$ A higher score indicates a higher HRQOL.

\section{Sense of coherence}

We used the short-form version of Sense of Coherence Scale (SOC-13, 13 items) at baseline to estimate the sense of coherence.

The SOC-13 has shown good acceptability among older people, ${ }^{44}$ has been used in several NH studies, ${ }^{26,45}$ and has shown high internal consistency in a review of 127 studies (Cronbach's alpha ranges from 0.70 to $0.92^{44}$ ). The SOC-13 is a seven-point rating scale with two anchor responses: "never" and "very often". The items measured were comprehensibility (believe that the challenge is understood) (five items), manageability (believe that resources to cope are available) (four items), and meaningfulness (be motivated to cope) (four items). The score ranges from 13 to 91, and higher score indicates a stronger SOC. ${ }^{22}$

\section{Statistical analysis}

We presented descriptive statistics as mean, range, and standard deviation (SD). To analyze HRQOL, we used a mixed linear model to regress each of the eight subscores on time for interview, age, sex, diagnosis of cancer, FCI, and sense of coherence. To study various developments over time for people with and without cancer, we tested the interactions between cancer and time. We similarly did this for time and sex and for sense of coherence and time. The mixed linear model accounts for correlations between the repeated measurements within each resident, assuming a compound symmetry correlation.

\section{Results Cohort demographics}

Of the 227 residents, 174 had died before the 5-year followup. Thus, 53 residents remained at 5 years, and 19 were alive after 6 years. Of these, 1 resident declined to participate and 52 completed follow-up assessment at 5 years; after 6 years, 1 resident declined to participate and 18 completed the follow-up. The mean age was 80 years (range 65-102), with $72 \%$ being women. Of the 18 respondents at followup, $11(62 \%)$ were women and the mean age was 84.8 years (SD: 7.6 years). The mean number of comorbid illnesses at baseline was 1.9 (median: 2.0, SD: 1.3, range: 0-5). The most common cancer diagnoses at baseline were breast cancer among women (20\%) and prostate cancer among men $(12 \%)$. Among both men and women, colorectal cancer was the second most common cancer that was diagnosed (18\%). The overall survival after 5 years was $17 \%$ for residents with cancer and $22 \%$ for residents without cancer. ${ }^{46}$

\section{Correlates of HRQOL}

The subscores for physical functioning and physical role limitation were both negatively correlated with time $(P<0.001$ and $P=0.02$, respectively) and physical functioning showed a linear trend. The other subscales, except general health and social functioning, were negatively correlated. None of the other subscales was significant. Having a diagnosis of cancer was negatively correlated with general health $(P=0.002)$. Sense of coherence was positively correlated with all the SF-36 subscales from baseline to follow-up in all subscores $(P<0.001)$. Cancer and time did not interact, nor did sex and time. The interaction between sense of coherence and time was not significant $(P=0.06)$. Compared with baseline, 
people with cancer reported more pain after 6 years. Table 1 presents all regression analysis outputs.

\section{Discussion}

The aim of this study was to investigate whether HRQOL among cognitively intact NHS residents changed over time during a 6-year follow-up period and whether sense of coherence and having a diagnosis of cancer influenced HRQOL among these individuals. Our longitudinal cohort study showed a change in HRQOL over time. This was observed for all subdimensions of the SF-36 after adjusting for age, sex, diagnosis of cancer, FCI, and sense of coherence. Of these, the physical functioning and role limitation-physical domains reached statistical significance.

These findings emphasize the specific impact on physical functioning over time and align closely with previously published work. This includes two separate studies ${ }^{14}$ among 65 community-dwelling older men and women and the general population, respectively, both of which reported a decline in physical health sum scores over 5 years. ${ }^{16}$ These findings were expected, since many studies ${ }^{11,12,47,48}$ report decline in physical functioning with increased age and that it is part of the aging process. ${ }^{48,49}$ This is particularly the case for NH residents, who frequently have multiple morbidities that, in turn, may affect physical functioning. ${ }^{48}$ Chronic conditions greatly influence the activities of daily living and dependence, ${ }^{48}$ which are critical factors driving major outcomes, including mortality. ${ }^{32,50,51}$ Of note, the findings of this study are in contrast to those published by Rønning and Stavem, ${ }^{17}$ in which HRQOL was reported to rise in the 6 months following an acute stroke. However, people experiencing acute stroke have a markedly different prognostic trajectory compared with people with cancer and other frail adults and often show improvement in overall functioning following the initial stroke event. This probably contributes to this differential finding.

A diagnosis of cancer was significantly negatively correlated with general health. This also correlates with previous work reporting poorer general health among older people with cancer compared with their healthy counterparts, both in the community and in NH. ${ }^{8,11,52}$ Poorer general health is closely associated with older age, presence of other chronic conditions, and types of cancer. ${ }^{11,53}$ The poorer health among $\mathrm{NH}$ residents with cancer in this study is also probably related to the decline in physical functioning, which has also previously been reported among older people in general ${ }^{54}$ and among people with cancer. ${ }^{54,55}$ Although the finding was not statistically significant, people with cancer reported more pain after 6 years compared with baseline in this study. $\mathrm{NH}$ residents with cancer often report pain, ${ }^{56,57}$ and untreated pain is probably an important factor for the decline in general health subdimensions.

With regard to the sense of coherence, this study demonstrated a positive correlation with all the SF-36 subdimensions after adjusting for age, sex, diagnosis of cancer, and FCI. These findings are in accordance with Antonovsky's view and with recent findings about the relationship between people's sense of coherence and quality of life. ${ }^{58}$ In light of this, the findings could suggest that a higher HRQOL is directly related to residents' ability to mobilize available resources to deal with challenges in everyday life and to experience meaning by doing this.

The stronger the sense of coherence, the better the quality of life. ${ }^{58}$ Thus, these findings indicate that strengthening the sense of coherence among $\mathrm{NH}$ residents could be a valuable means of improving well-being. The work also highlights the potential value of monitoring residents' sense of coherence and investigating means of improving it as a route to improving HRQOL. There are several potential approaches to achieve this, such as identifying residents' previous strengths and the resources they can use within their current physical limitations. These approaches would require clear training for $\mathrm{NH}$ personnel to enable them to build on this and provide understandable information on health care, inform the residents about the resources available, and assist the residents in using them. Interventions and strategies to strengthen sense of coherence could be important. This will be an interesting area to pursue for future research. For example, Langeland et a ${ }^{59}$ have shown that therapy groups based on salutogenic treatment principles improve coping among people with mental health problems, and the manageability component contributed most to this improvement.

\section{Strengths and limitations}

This study has provided robust, high-quality data by using in-depth data collected on HRQOL and sense of coherence that have allowed clear conclusions to be drawn. Importantly, very few data were missing from the HRQOL and SOC-13 at baseline and at follow-up. Additional strengths of the study include the high response rate of surviving participants and that the care personnel in the $\mathrm{NH}$ were not directly involved in the interviews performed by the principal investigator (JD). However, there are limitations. The sample size is fairly small, and surviving participants may not be representative of the wider $\mathrm{NH}$ population. The small number of residents alive after 6 years could also have been the fittest residents 


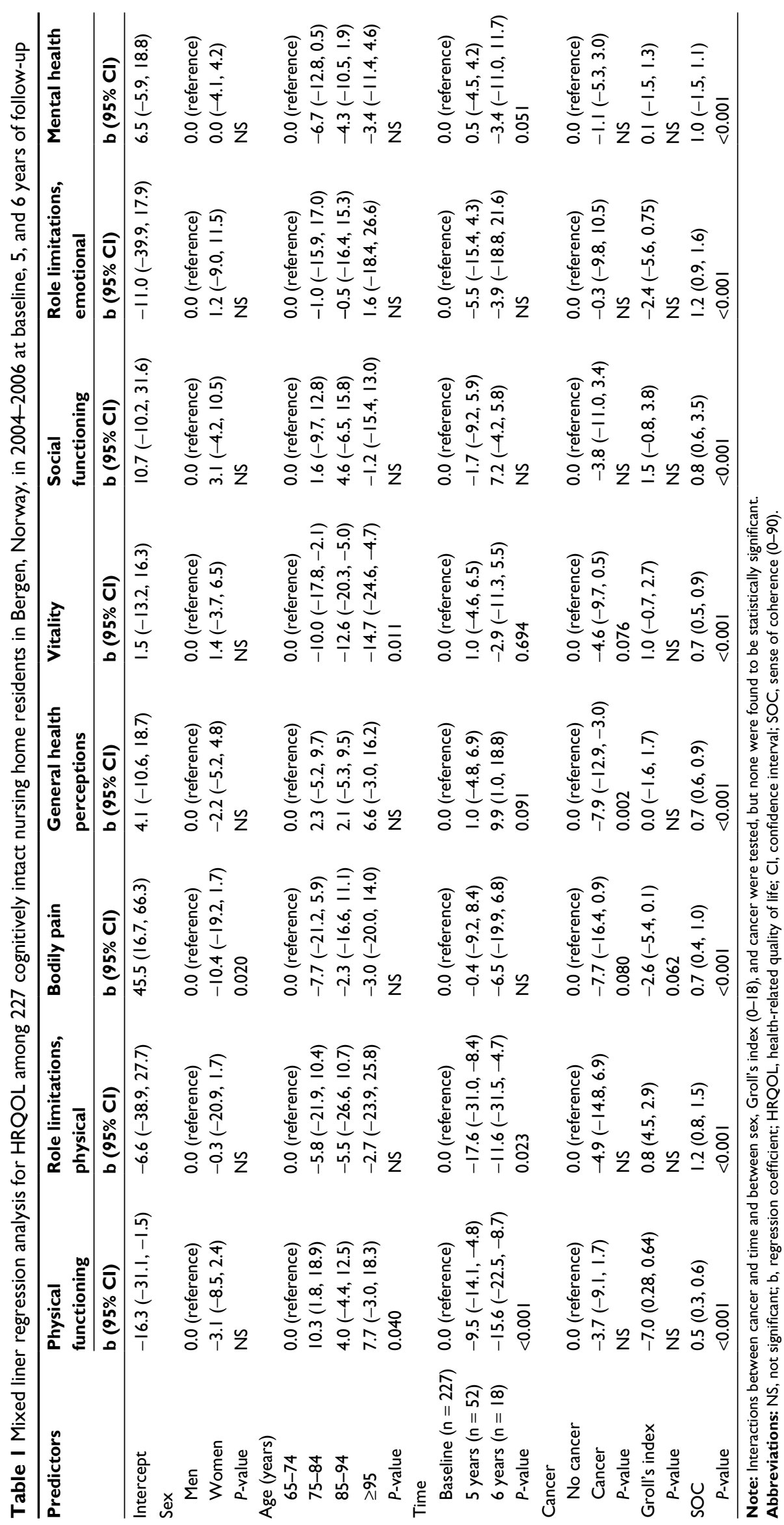


from the beginning and may have overcome their diagnosis of cancer or been in remission.

Further, information could not be gathered about the time since cancer was diagnosed and about whether the residents were diagnosed after being admitted to an NH. These factors may influence HRQOL. ${ }^{11}$ Thus, further research is needed to substantiate these findings.

\section{Conclusion}

This study indicates that the HRQOL changes over time in $\mathrm{NH}$ residents and indicates that sense of coherence is an important component of the change in the HRQOL. Finally, this study has shown that having a diagnosis of cancer is clearly associated with a decline in general health. Follow-up studies with a larger sample size in the same age groups are needed to study this relationship more carefully.

\section{Disclosure}

The authors report no conflicts of interest in this work.

\section{References}

1. National Institute on Aging. Global health and aging. Available from: http://www.nia.nih.gov/research/publication/global-health-andaging/living-longer. Accessed January 10, 2017.

2. Statistics Norway. StatBank Norway. Available from: https://www.ssb. no/statistikkbanken/selectvarval/saveselections.asp. Accessed January 10, 2017.

3. Harris-Kojetin L, Sengupta M, Park-Lee E, et al. Long-term care providers and services users in the United States: data from the National Study of Long-Term Care Providers, 2013-2014. Vital Health Stat 3. 2016;38:x-xii; 1-105.

4. European Commission. Long-term care beds in nursing and residential care facilities. Available from: http://ec.europa.eu/eurostat/statisticsexplained/index.php/Healthcare_resource_statistics_-_beds\#Longterm_care_beds_in_nursing_and_residential_care_facilities. Accessed January 10, 2017.

5. Drageset J, Eide GE, Harrington C, Ranhoff AH. Acute hospital admission for nursing home residents without cognitive impairment with a diagnosis of cancer. Eur J Cancer Care (Engl). 2015;24(2):147-154.

6. Selbaek G, Kirkevold Ø, Engedal K, Selbaek G, Kirkevold O, Engedal $\mathrm{K}$. The prevalence of psychiatric symptoms and behavioural disturbances and the use of psychotropic drugs in Norwegian nursing homes. Int J Geriatr Psychiatry. 2007;22(9):843-849.

7. Drageset J, Eide GE, Ranhoff AH. Cancer in nursing homes: characteristics and health-related quality of life among cognitively intact residents with and without cancer. Cancer Nurs. 2012;35(4):295-301.

8. Drageset J, Eide GE, Ranhoff AH. Depression is associated with poor functioning in activities of daily living among nursing home residents without cognitive impairment. J Clin Nurs. 2011;20(21-22): 3111-3118.

9. Gozalo P, Plotzke M, Mor V, Miller SC, Teno JM. Changes in Medicare costs with the growth of hospice care in nursing homes. $N$ Engl J Med. 2015;372(19):1823-1831.

10. Parry C, Kent EE, Mariotto AB, Alfano CM, Rowland JH. Cancer survivors: a booming population. Cancer Epidemiol Biomarkers Prev. 2011;20(10):1996-2005.

11. Smith AW, Reeve BB, Bellizzi KM, et al. Cancer, comorbidities, and health-related quality of life of older adults. Health Care Financ Rev. 2008;29(4):41-56.
12. Colón-Emeric CS, Whitson HE, Pavon J, Hoenig H. Functional decline in older adults. Am Fam Physician. 2013;88(6):388-394.

13. Duncan JG, Bott MJ, Thompson SA, Gajewski BJ. Symptom occurrence and associated clinical factors in nursing home residents with cancer. Res Nurs Health. 2009;32(4):453-464.

14. Der-Martirosian C, Kritz-Silverstein D, Barrett-Connor E. Five-year stability in associations of health-related quality of life measures in community-dwelling older adults: the Rancho Bernardo Study. Qual Life Res. 2010;19(9):1333-1341.

15. Wong MS, Chair SY. Changes in health-related quality of life following percutaneous coronary intervention: a longitudinal study. Int $J$ Nurs Stud. 2007;44(8):1334-1342.

16. Hopman WM, Berger C, Joseph L, et al; CaMos Research Group. The natural progression of health-related quality of life: results of a five-year prospective study of SF-36 scores in a normative population. Qual Life Res. 2006;15(3):527-536.

17. Rønning OM, Stavem K. Determinants of change in quality of life from 1 to 6 months following acute stroke. Cerebrovasc Dis. 2008;25(1-2): $67-73$.

18. Donnally CJ 3rd, Gupta A, Bensalah K, et al. Longitudinal evaluation of the SF-36 quality of life questionnaire in patients with kidney stones. Urol Res. 2011;39(2):141-146.

19. Buckinx F, Reginster JY, Petermans J, et al. Relationship between frailty, physical performance and quality of life among nursing home residents: the SENIOR cohort. Aging Clin Exp Res. 2016;28(6):1149-1157.

20. Hartog LC, Landman GW, Cimzar-Sweelssen M, et al. Health-related quality of life, rehabilitation and mortality in a nursing home population. Neth J Med. 2016;74(6):247-256.

21. Xiao H, Yoon JY, Bowers B. Quality of life of nursing home residents in China: a mediation analysis. Nurs Health Sci. Epub 2016 June 9.

22. Antonovsky A. Unraveling the Mystery of Health: How People Manage Stress and Stay Well. San Francisco: Jossey Bass; 1987.

23. Ekman I, Fagerberg B, Lundman B. Health-related quality of life and sense of coherence among elderly patients with severe chronic heart failure in comparison with healthy controls. Heart Lung. 2002;31(2): 94-101.

24. Kattainen E, Meriläinen P, Sintonen H. Sense of coherence and healthrelated quality of life among patients undergoing coronary artery bypass grafting or angioplasty. Eur J Cardiovasc Nurs. 2006;5(1):21-30.

25. Nygren B, Aléx L, Jonsén E, Gustafson Y, Norberg A, Lundman B. Resilience, sense of coherence, purpose in life and self-transcendence in relation to perceived physical and mental health among the oldest old. Aging Ment Health. 2005;9(4):354-362.

26. Drageset J, Nygaard HA, Eide GE, Bondevik M, Nortvedt MW, Natvig GK. Sense of coherence as a resource in relation to health-related quality of life among mentally intact nursing home residents - a questionnaire study. Health Qual Life Outcomes. 2008;6:85.

27. Franklin LL, Ternestedt BM, Nordenfelt L. Views on dignity of elderly nursing home residents. Nurs Ethics. 2006;13(2):130-146.

28. Cole CS. Nursing home residents' sense of coherence and functional status decline. J Holist Nurs. 2007;25(2):96-103.

29. Eriksson M, Lindström B. Antonovsky's sense of coherence scale and the relation with health: a systematic review. J Epidemiol Community Health. 2006;60(5):376-381.

30. Helvik AS, Engedal K, Selbæk G. Sense of coherence and quality of life in older in-hospital patients without cognitive impairment - a 12 month follow-up study. BMC Psychiatry. 2014;14:82.

31. Borowiak E, Kostka T. Predictors of quality of life in older people living at home and in institutions. Aging Clin Exp Res. 2004;16(3):212-220.

32. Idler EL, Benyamini Y. Self-rated health and mortality: a review of twenty-seven community studies. J Health Soc Behav. 1997;38(1):21-37.

33. Wedding U, Pientka L, Höffken K. Quality-of-life in elderly patients with cancer: a short review. Eur J Cancer. 2007;43(15):2203-2210.

34. Hughes CP, Berg L, Danziger WL, Coben LA, Martin RL. A new clinical scale for the staging of dementia. Br J Psychiatry. 1982;140:566-572.

35. Morris JC. The Clinical Dementia Rating (CDR): current version and scoring rules. Neurology. 1993;43(11):2412-2414. 
36. Groll DL, To T, Bombardier C, Wright JG. The development of a comorbidity index with physical function as the outcome. J Clin Epidemiol. 2005;58(6):595-602.

37. Ware JE Jr, Sherbourne CD. The MOS 36-item short-form health survey (SF-36). I. Conceptual framework and item selection. Med Care. 1992;30(6):473-483.

38. Ferrucci L, Guralnik JM, Studenski S, Fried LP, Cutler GB Jr, Walston JD; Interventions on Frailty Working Group. Designing randomized, controlled trials aimed at preventing or delaying functional decline and disability in frail, older persons: a consensus report. J Am Geriatr Soc. 2004;52(4):625-634.

39. Ware JE, Snow KK, Kosinski M, Gandek B. SF-36 Health Survey: Manual and Interpretation Guide. Boston: New England Medical Center, the Health Institute; 1993.

40. Lyons RA, Perry HM, Littlepage BN. Evidence for the validity of the Short-form 36 Questionnaire (SF-36) in an elderly population. Age Ageing. 1994;23(3):182-184.

41. Pit SW, Schurink J, Nair BR, Byles J, Heller RF. Use of the short-form-36 health survey to assess quality of life among Australian elderly. Aust J Ageing. 1996;15:132-135.

42. Anderson KL, Burckhardt CS. Conceptualization and measurement of quality of life as an outcome variable for health care intervention and research. J Adv Nurs. 1999;29(2):298-306.

43. Ware JE, Gandek B; IQOLA Project Group. The SF-36 health survey: development and use in mental health research and the IQOLA project. Int J Ment Health. 1994;23(2):49-73.

44. Eriksson M, Lindström B. Validity of Antonovsky's sense of coherence scale: a systematic review. J Epidemiol Community Health. 2005; 59(6):460-466.

45. Forsberg KA, Björkman T, Sandman PO, Sandlund M. Influence of a lifestyle intervention among persons with a psychiatric disability: a cluster randomised controlled trail on symptoms, quality of life and sense of coherence. J Clin Nurs. 2010;19(11-12):1519-1528.

46. Drageset J, Eide GE, Ranhoff AH. Anxiety and depression and mortality among cognitively intact nursing home residents with and without a cancer diagnosis: a 5-year follow-up study. Cancer Nurs. 2013;36(4):E68-E74

47. Kurtz ME, Kurtz JC, Stommel M, Given CW, Given B. Loss of physical functioning among geriatric cancer patients: relationships to cancer site, treatment, comorbidity and age. Eur J Cancer. 1997;33(14):2352-2358.
48. Bellizzi KM, Rowland JH. Role of comorbidity, symptoms and age in the health of older survivors following treatment for cancer. Aging Health. 2007;3:625-635.

49. Leach CR, Weaver KE, Aziz NM, et al. The complex health profile of long-term cancer survivors: prevalence and predictors of comorbid conditions. J Cancer Surviv. 2015;9(2):239-251.

50. Thomas JM, Cooney LM Jr, Fried TR. Systematic review: healthrelated characteristics of elderly hospitalized adults and nursing home residents associated with short-term mortality. J Am Geriatr Soc. 2013;61(6):902-911.

51. Drageset J, Eide GE, Ranhoff AH. Mortality in nursing home residents without cognitive impairment and its relation to self-reported health-related quality of life, sociodemographic factors, illness variables and cancer diagnosis: a 5-year follow-up study. Qual Life Res. 2013;22(2):317-325.

52. Hewitt M, Rowland JH, Yancik R. Cancer survivors in the United States: age, health, and disability. J Gerontol A Biol Sci Med Sci. 2003; 58(1):82-91.

53. Baker F, Haffer SC, Denniston M. Health-related quality of life of cancer and noncancer patients in Medicare managed care. Cancer. 2003; 97(3):674-681.

54. Moreh E, Jacobs JM, Stessman J. Fatigue, function, and mortality in older adults. J Gerontol A Biol Sci Med Sci. 2010;65(8):887-895.

55. Avis NE, Deimling GT. Cancer survivorship and aging. Cancer. 2008; 113(12 Suppl):3519-3529.

56. Pimentel CB, Briesacher BA, Gurwitz JH, Rosen AB, Pimentel MT, Lapane KL. Pain management in nursing home residents with cancer. J Am Geriatr Soc. 2015;63(4):633-641.

57. Drageset J, Corbett A, Selbaek G, Husebo BS. Cancer-related pain and symptoms among nursing home residents: a systematic review. J Pain Symptom Manage. 2014;48(4):699-710.e1.

58. Eriksson M, Lindström B. Antonovsky's sense of coherence scale and its relation with quality of life: a systematic review. J Epidemiol Community Health. 2007;61(11):938-944.

59. Langeland E, Riise T, Hanestad BR, Nortvedt MW, Kristoffersen K, Wahl AK. The effect of salutogenic treatment principles on coping with mental health problems. A randomised controlled trial. Patient Educ Couns. 2006;62(2):212-219.
Patient Related Outcome Measures

\section{Publish your work in this journal}

Patient Related Outcome Measures is an international, peer-reviewed, open access journal focusing on treatment outcomes specifically relevant to patients. All aspects of patient care are addressed within the journal and practitioners from all disciplines are invited to submit their work as well as healthcare researchers and patient support groups.

\section{Dovepress}

The journal is included in PubMed. The manuscript management system is completely online and includes a very quick and fair peer-review system. Visit http://www.dovepress.com/testimonials.php to read real quotes from published authors. 